\title{
Plastering mud around the entrance hole affects the estimation of threat levels from nest predators in Eurasian Nuthatches
}

\author{
Jiangping Yu' ${ }^{1}$, Li Zhang ${ }^{1}$, Guodong Yi², Keqin Zhang ${ }^{3 *} \mathbb{D}$, Jiyuan Yao ${ }^{4}$, Jian Fang ${ }^{2}$, Chao Shen ${ }^{5}$ and \\ Haitao Wang ${ }^{1,5^{*}}$
}

\begin{abstract}
Background: For cavity-nesting birds, the nest entrance plays an important role in preventing predators from accessing nests. Several species of nuthatches use mud to narrow the entrance of cavities. In theory, the smaller the entrance hole size, the more effective it is against predators; however, few studies have tested whether narrowing the entrance hole size can affect the estimation of threat levels from nest predators in cavity-nesting birds.

Methods: Using dummy experiments, we tested whether Eurasian Nuthatches (Sitta europaea, narrow the entrance hole of cavities) and Cinereous Tits (Parus cinereus, do not narrow the entrance hole, as a control) perform different nest defence behaviours against Common Chipmunks (Tamias sibiricus, small nest predator) and Red Squirrels (Sciurus vulgaris, larger nest predator).

Results: Both nuthatches and tits exhibited stronger response behaviours (high dummy response scores) against chipmunks than against squirrels. Compared with tits, nuthatches exhibited more aggressive behaviours to chipmunks, but their responses to squirrels were similar.

Conclusions: Nest defence behaviours of nuthatches to chipmunks differed from tits, and the results suggested that nuthatches might estimate threat levels of nest predators according to their narrowed entrance-hole size.
\end{abstract}

Keywords: Cavity-nesting birds, Entrance-hole size, Eurasian Nuthatches, Nest defence behaviour, Nest predator

\section{Background}

Nest predation is the most important factor impeding successful breeding in birds (Ricklefs 1969; Martin 1995; Caro 2005; Lima 2009). Under such selection pressure, birds have evolved complex anti-predation strategies to protect their nests and perform specific nest defence behaviours when facing different types or

\footnotetext{
*Correspondence: kqzhang01@hotmail.com; wanght402@nenu.edu.cn 1 Jilin Engineering Laboratory for Avian Ecology and Conservation Genetics, School of Life Sciences, Northeast Normal University, Changchun 130024, China

${ }^{3}$ School of Zoological Science, Jilin Agricultural Science and Technology University, Jilin 132109, China

Full list of author information is available at the end of the article
}

risk levels of predators (Lima et al. 2005; Yorzinski and Vehrencamp 2009; Yorzinski and Platt 2012; Mahr et al. 2015; Suzuki 2015; Maziarz et al. 2018). Although nest defence by parents can increase the survival possibility of offspring, it also costs defenders in terms of time and energy expenditure and injury or death caused by predators (Montgomerie and Weatherhead 1988). Both underestimating or overestimating the danger posed by a predator can be detrimental for parents (Caro 2005). Therefore, parent birds should choose the right nest defence strategy when defending their offspring against predators, including making a decision about whether and how intensively to defend their nests (e.g. Caro 2005; Mahr et al. 2015). 
Distinguishing different predators and their threat levels is the first step to effectively avoid predators. The body size of a predator is a reliable indicator of the threat level that it poses to birds (Swaisgood et al. 1999), and it is especially important in some predators that they are quite similar in overall appearance as well as body shape (Beránková et al. 2014). It has been shown that various bird species can distinguish between raptors differing in size and then perform appropriate antipredator response behaviours (Evans et al. 1993; Templeton et al. 2005; Courter and Ritchison 2010). However, many factors, such as habitat, nest stage, sex, nest type and predator location, may influence and cause changes in nest defence behaviour of birds (Burger 1992; Ritchison 1993; Møller et al. 2016; Crisologo and Bonter 2017). For example, alarm calling rates increased with the nesting stage in Southern House Wrens (Troglodytes musculus) (Fasanella and Fernández 2009).

Generally, cavity-nesting birds are better protected against nest predator's attacks than open-cup nesters (Martin and Li 1992), as nest entrance can play a role in preventing predator's access to nests (Wesołowski 2002). However, nest predation is still the main cause of reproductive failure for cavity-nesting species (Lima 2009). Some predators can enter the nest cavity if the entrance of a hole is sufficiently large, such as chipmunks, snakes and small owls (Solheim 1984; Suzuki 2011; Yu et al. 2020). A cavity with a small entrance size can prevent more predators from entering and plundering the nest than a cavity with a large entrance size (Wesołowski 2002). Therefore, the body size of a nest predator, in theory, should indicate the level of threat that they pose to cavity-nesting birds.

Secondary cavity-nesting species are unable to excavate their own nest holes, and they depend on cavities created by primary excavators (e.g., woodpeckers) and natural decay processes (Newton 1994). Most secondary cavitynesting species build their nests, which are placed at the base of the cavity, and do not adjust the entrance of holes, such as the Mandarin Duck (Aix galericulata). Several Sitta nuthatches have the ability to narrow the cavity entrance by plastering mud around the openings (Matthysen 1998; Wesołowski and Rowiński 2004; Strubbe and Matthysen 2009). In theory, a smaller entrance hole size should give nuthatches an advantage as protection against larger predators (Wesołowski 2002). However, few studies have tested whether narrowing the entrance hole size can affect the estimation of threat levels from nest predators in cavity-nesting birds.

Eurasian Nuthatches (Sitta europaea, nuthatches hereafter) breed in nest boxes (the range of the entrance hole size was 4.5 to $6.5 \mathrm{~cm}$, see details below) in our study area. They usually narrow the entrance hole of a nest box to approximately $2.5 \mathrm{~cm}$ by using mud. Common Chipmunks (Tamias sibiricus, chipmunk hereafter) and Red Squirrels (Sciurus vulgaris, squirrel hereafter) are nest predators of nesting cavity, as they enter nests to destroy the nest cup and eat the eggs and chicks. Chipmunks can enter most nest boxes easily due to their small body size (head-and-body length is approximately $130 \mathrm{~cm}$ ), but squirrels (approximately $200 \mathrm{~cm}$, Piao et al. 2013) are rarely found in nest boxes with entrance hole sizes $<4.5 \mathrm{~cm}$. Here, we tested whether Eurasian Nuthatches perform different nest defence behaviours against chipmunks and squirrels according to their adjusted entrance hole size. If mud around the entrance prevents nest predators from entering, we expected nuthatches to exhibit stronger nest defence behaviours in chipmunks than in squirrels.

\section{Methods}

\section{Study area and subjects}

Our experiments were carried out in Zuojia Nature Reserve $\left(44^{\circ} 1^{\prime}-45^{\circ} 0^{\prime} \mathrm{N}, 126^{\circ} 0^{\prime}-126^{\circ} 8^{\prime} \mathrm{E}\right)$ in Jilin, northeastern China. The vegetation within the study area was diverse, with a continental monsoon climate and four distinct seasons in the temperate zone, although the existing forest was secondary ( $\mathrm{E}$ et al. 2019; Liu et al. 2019). We attached nest boxes to trees approximately 3-4 m above the ground, and the number of nest boxes distributed in Zuojia was maintained at approximately 450 per year (Yu et al. 2017a). The entrance hole size of an original artificial nest box in our study area was $4.5 \mathrm{~cm}$. However, woodpeckers often peck holes in nest boxes, which results in expansion of the entrance hole size up to a maximum of $6.5 \mathrm{~cm}$. If a pecked nest box can still be used by birds, we will not replace it. Thus, the range of the entrance hole size of an artificial nest box in our study area was 4.5 to $6.5 \mathrm{~cm}$.

During the breeding season, the total number of nests used by birds in the study area was approximately 180 (including 10-20 pecked nest boxes) per year. In addition to secondary cavity-nesting birds, rodent chipmunks and squirrels are also bred in artificial nest boxes. Based on our observations, the population size of squirrels was slightly larger than that of chipmunks. The numbers of nest boxes used by chipmunks and squirrels were approximately 10-15 nests and 1-2 nests per year, respectively. The nest boxes were checked at intervals of 5-7 days from March to July to determine occupancy, and we classified boxes with at least one egg as occupied (E et al. 2019).

Previous studies found that nuthatches exhibit significantly different nest defence behaviours than terrestrial and aerial nest predators (Matthysen 1998; Sun et al. 2017; Nad'o et al. 2018). They usually exhibit specific 
aggressive behaviours in terrestrial vertebrates, such as hovering over and spreading out wings and tails (Sun et al. 2017). Therefore, we did not pose any other species dummy to nuthatches as a neutral or negative control in this study. Instead, we chose another cavity-nesting bird species, Cinereous Tits (Parus cinereus, tits hereafter), as a positive control. Nuthatches and tits are small cavity-nesting birds with similar body sizes. Tits do not adjust the entrance hole, while nuthatches use mud to narrow the entrance. Here, we compared the intensity of defence behaviours of nuthatches and tits to the same nest predators.

\section{Dummy experiments}

During the nestling period of Eurasian Nuthatches ( $n=17$ nests) and Cinereous Tits $(n=20$ nests, 6 of the 20 nesting boxes were pecked by woodpeckers), we presented taxidermic dummies of Common Chipmunks (small nest predator, 2 models) and Red Squirrels (large nest predator, 2 models) above the nest boxes. The trials were conducted during sunny days between 8:30 a.m. and 5:00 p.m., from May 10 to June 1, 2019, and each nest received two dummy presentations in a random order. Video recorders were set up to record the experimental process. We scored the dummy responses (response scores hereafter) of nuthatches and tits on a five-point scale: (i) entered the nest; (ii) produced alarm calls during stationary observation; (iii) produced alarm calls with agitated skipping and flicking of wings; (iv) approached the rodent closely and hovered over it, spreading their wings and tail, or performed attack behaviour with no physical encounter; and (v) performed attack behaviour with physical impact (Liang and Møller 2015; Yu et al. 2017a; 2019). As the birds often attacked nest predators, we also quantified aggressive behaviour by counting the number of contact attacks of focal parent birds (attack numbers hereafter, we counted the exact number of attacks indoors by playing back the video). This enabled us to determine the primary target of attacks of the defending parents.

\section{Statistical analysis}

All data were analysed using R 3.6.1 software (http:// www.r-project.org). For the response scores (ranked response, 5 levels) of nuthatches and tits, cumulative link mixed models (CLMMs, clmm in R package ordinal) with logit-link function were used, and we used two-tailed likelihood ratio tests to obtain $P$ values. For attack numbers of nuthatches and tits, generalized linear mixed models (GLMMs, glmer in R package lme4) with a Poisson error structure and log-link function were used, and we calculated $P$ values using Wald Chi-square tests with the Anova function in the car package. In the model, response scores or attack numbers were the dependent variable, whereas bird species, treatment and order of treatment exposure were treated as fixed terms, and individuals distinguishing birds' nests were random terms. If there was a significant effect of bird species and treatment, we further performed post hoc pairwise comparisons between species and treatments. To reduce the probability of type I errors, Bonferroni correction was used to adjust $P$ values (P.adjust function in the R package stats, Rice 1989; Yu et al. 2017b).

\section{Results}

The dummy response scores of nuthatches and tits differed significantly between species (CLMMs, $\chi_{1}^{2}=10.50$, $P=0.001)$ and treatments $\left(\chi_{1}^{2}=20.16, P<0.001\right)$, while there were no significant effects of trial order $\left(\chi_{1}^{2}=0.02\right.$, $P=0.88$ ) on dummy response scores. The dummy response scores of nuthatches (adjusted $P<0.001$ ) and tits (adjusted $P=0.047$ ) were sufficiently stronger to chipmunks than to squirrels (Fig. 1). In addition, the dummy response scores of nuthatches to chipmunks were sufficiently stronger than those of tits to chipmunks (adjusted $P<0.001)$. The dummy response scores of nuthatches and tits to squirrels were similar (adjusted $P=1.000$ ).

The number of attacks of nuthatches and tits differed significantly between species (GLMMs, $\chi_{1}^{2}=12.96$, $P<0.001)$ and treatments $\left(\chi_{1}^{2}=63.52, P<0.001\right)$, while there were no significant effects of trial order $\left(\chi_{1}^{2}=2.52\right.$, $P=0.11)$ on attack numbers. Nuthatches attacked chipmunks significantly more strongly than squirrels (adjusted $P<0.001$, Fig. 2). In contrast, tits rarely attacked chipmunks and squirrels (adjusted $P=1.000$ ).

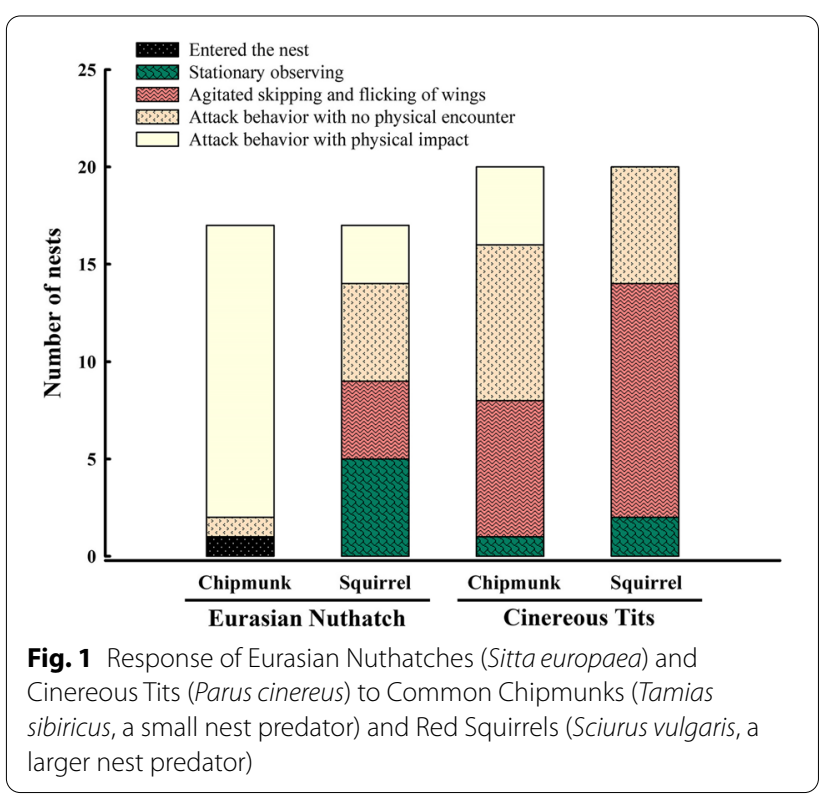


The number of attacks of nuthatches to chipmunks were greater than those of tits to chipmunks (adjusted $P=0.001$ ). The number of attacks of nuthatches and tits to squirrels were similar (adjusted $P=1.000$ ).

\section{Discussion}

In our study, both nuthatches and tits exhibited stronger response behaviours (high dummy response scores) to chipmunks than to squirrels. For parents, nest defence behaviours (e.g., defensive displays and direct attacks) may enhance their reproductive success (Montgomerie and Weatherhead 1988). However, decision-making in active nest defence is quite a complex process, and threat levels of predators to broods should be taken into account (Kleindorfer et al. 2005). Chipmunks and squirrels pose the same kind of nest predation threat to cavity birds, as they can enter nests to destroy the nest contents. However, chipmunks are major nest predators in our study area, and squirrels may occasionally exhibit opportunistic omnivory. Even nuthatches used mud to narrow their entrance hole, which could completely prevent squirrels but not chipmunks from entering because chipmunks could remove a part of the mud to gain access to enter the cavity (Wesołowski 2002). Our study results indicated that nuthatches and tits could discriminate rodents differing in size, and the predatory threat of chipmunks to their offspring was higher than that of squirrels.

The number of attacks could reflect the degree of aggressiveness of the attacks (Fuchs et al. 2019). In our study, nuthatches attacked chipmunks significantly more strongly than squirrels (Fig. 2), while tits rarely attacked them. Parents attacking nest predators directly may be

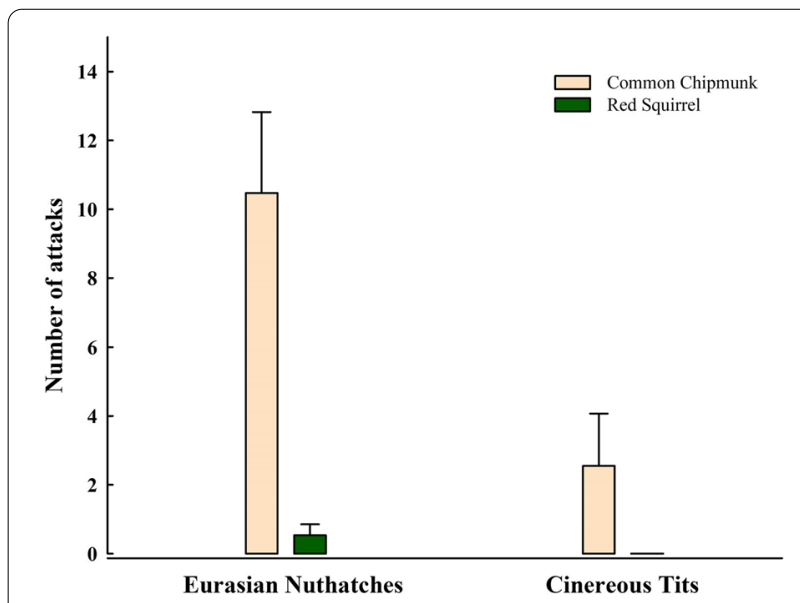

Fig. 2 The number of attacks of Eurasian Nuthatches and Cinereous Tits to Common Chipmunks and Red Squirrels. Error bars represent standard error of the mean more efficient and result in successfully deterring predators from the brood. However, anti-predator behaviour is usually energetically taxing (Krams and Krama 2002), and defending parents experience risk of injury or death (Brunton 1986; Montgomerie and Weatherhead 1988; Sordahl 1990). Here, specific attacking behaviours against the more dangerous chipmunks were most likely an antipredator strategy for nuthatches, which may help them to reduce the energy costs of unnecessary aggressive behaviours (Polak 2013; Kryštofková et al. 2011; Yu et al. 2016). Based on our field observations, tits were unlikely to succeed in protecting their nest contents from invading nest predators by performing aggressive behaviours. Then, enacting displays with a moderate or low degree of aggression to nest predator chipmunks and squirrels could enable tits to avoid unnecessary investment in costly attacks (Polak 2013).

In this study, dummy response scores and attack numbers of nuthatches to chipmunks were significantly higher than those of tits to chipmunks, while the response behaviours of nuthatches and tits to squirrels were similar. Parental behaviours are selected to maximize lifetime reproductive success, and nest defence intensity of parent birds will also be influenced by the benefit for the current brood versus future reproduction (Trivers 1972; Smith 1977). Both Eurasian Nuthatches and Cinereous Tits are short-lived birds and have similar lifespans, but the possibility of repeating a lost brood during one breeding season differs between them. The population of Cinereous Tits in our study area can produce a second brood immediately after the failure of the first brood effort, while Eurasian Nuthatches only produce one large brood per year. Thus, nuthatches should have a stronger incentive to attempt to drive dangerous nest predators away through active nest defence behaviours (Curio 1978) because saving energy for future broods is a rather unlikely strategy. For tits, the probability of re-nesting may play a major role in their risk taking; therefore, they might be at less risk for their current brood than a bird with a lower renesting potential (Curio et al. 1984; Ghalambor and Martin 2000, 2001).

\section{Conclusions}

Nuthatches and tits exhibited different nest defence behaviours against the same nest predators, and the results showed that those two species implemented different nest defence strategies. If a nest intruder does not represent an immediate threat to the nest, it is more advantageous for nest owners to refrain from aggressive behaviour (Kryštofková et al. 2011). Moreover, the compromise between current and future reproduction should be taken into account for defence intensity towards a threat posed to the offspring (Caro 2005). Results of the present study 
suggested that nuthatches might estimate threat levels of nest predators according to their narrowed entrance-hole size. Future studies should determine if mud around the entrance can play an important role in preventing nest predators with different sizes from entering, which in turn may help us to understand the functions of plastering mud in nuthatches.

\section{Acknowledgements}

We are grateful to Dongxu Li and Junlong Yin for assistance with fieldwork. We also thank Zuojia Nature Reserve for their support and permit to carry out this study.

\section{Authors' contributions}

HW, KZ and J. Yu conceived the idea and formulated questions. JF, GY and CS performed the experiments. JF and LZ analyzed data. J. Yu and LZ wrote the manuscript. J. Yao contributed substantial materials. HW, KZ and J. Yu contributed resources and funding. All authors read and approved the final manuscript.

\section{Funding}

This work is supported by the National Natural Science Foundation of China (No. 31870368 to KZ, No. 31770419 and No. 31971402 to HW, No. 32001094 to J. Yu), and the Science and Technology Project Program of Jilin Provincial Department of Education (JJKH20190281KJ to J. Yu).

\section{Availability of data and materials}

The datasets used and analyzed in this study are available from the corresponding author on reasonable request.

\section{Declarations}

\section{Ethics approval and consent to participate}

The experiments comply with the current laws of China. Fieldwork was carried out under the permission from Zuojia Nature Reserves, Jilin, China. Experimental procedures were permitted by National Animal Research Authority in Northeast Normal University (Approval Number: NENU-20080416) and the Forestry Bureau of Jilin Province of China (Approval Number: [2006]178).

\section{Consent for publication}

Not applicable.

\section{Competing interests}

The authors declare that they have no competing interests.

\begin{abstract}
Author details
${ }^{1}$ Jilin Engineering Laboratory for Avian Ecology and Conservation Genetics, School of Life Sciences, Northeast Normal University, Changchun 130024, China. ${ }^{2}$ School of Life Sciences, Jilin Normal University, Siping 136000, China. ${ }^{3}$ School of Zoological Science, Jilin Agricultural Science and Technology University, Jilin 132109, China. ${ }^{4}$ College of Animal Science and Technology, Jilin Agricultural University, Chang chun 130118, China. ${ }^{5}$ Jilin Key Laboratory of Animal Resource Conservation and Utilization, Northeast Normal University, Changchun 130024, China.
\end{abstract}

Received: 31 March 2021 Accepted: 24 October 2021

Published online: 02 November 2021

\section{References}

Beránková J, Veselý P, Sýkorová J, Fuchs R. The role of key features in predator recognition by untrained birds. Anim Cogn. 2014;17:963-71.

Brunton DH. Fatal antipredator behavior of killdeer. Wilson Bull. 1986;98:605-7.

Burger SJ. Differential responses of tropical roseate terns to aerial intruders throughout the nesting cycle. Condor. 1992;94:712-9.

Caro TM. Antipredator defenses in birds and mammals. Chicago: University of Chicago Press; 2005
Courter JR, Ritchison G. Alarm calls of tufted titmice convey information about predator size and threat. Behav Ecol. 2010;21:936-42.

Crisologo TL, Bonter DN. Defending the weak: parental defense peaks when chick vulnerability is greatest in the herring gull Larus argentatus. Ethology. 2017;123:113-22.

Curio E. The adaptive significance of avian mobbing. I. Teleonomic hypotheses and predictions. Z Tierpsychol. 1978;48:175-83.

Curio E, Regelmann K, Zimmermann U. The defence of first and second broods by great tit Parus major parents: a test of predictive sociobiology. $Z$ Tierpsychol. 1984;66:101-27.

Evans C, Macedonia J, Marler P. Effects of apparent size and speed on the response of chickens, Gallus gallus, to computer-generated simulations of aerial predators. Anim Behav. 1993;46:1-11.

Fasanella M, Fernández GJ. Alarm calls of the southern house wren Troglodytes musculus: variation with nesting stage and predator model. J Ornithol. 2009:150:853-63.

Fuchs R, Veselý P, Nácarová J. How to study predator recognition. In: Fuchs R, Veselý P, Nácarová J, editors. Predator recognition in birds. The use of key features. Switzerland: Springer International Publishing; 2019.

Ghalambor CK, Martin TE. Parental investment strategies in two species of nuthatch vary with stage-specific predation risk and reproductive effort. Anim Behav. 2000;60:263-7.

Ghalambor CK, Martin TE. Fecundity-survival trade-offs and parental risk-taking in birds. Science. 2001;292:494-7.

Kleindorfer S, Fessl B, Hoi H. Avian nest defence behaviour: assessment in relation to predator distance and type, and nest height. Anim Behav. 2005:69:307-13.

Krams I, Krama T. Interspecific reciprocity explains mobbing behaviour of the breeding chaffinches, Fringilla coelebs. Proc R Soc B. 2002;269:2345-50.

Kryštofková M, Haas M, Exnerová A. Nest defence in blackbirds Turdus merula: effect of predator distance and parental sex. Acta Ornithol. 2011;46:55-63.

Liang W, Møller AP. Hawk mimicry in cuckoos and antiparasitic aggressive behavior of barn swallows in Denmark and China. J Avian Biol. 2015;46:216-23.

Lima SL. Predators and the breeding bird: behavioral and reproductive flexibility under the risk of predation. Biol Rev. 2009;84:485-513.

Lima SL, Rattenborg NS, Lesku JA, Amlaner CJ. Sleeping under the risk of predation. Anim Behav. 2005;70:723-36.

Liu J, Yang C, Yu J, Wang H, Liang W. Egg recognition in Cinereous Tits Parus cinereus: eggshell spots matter. Avian Res. 2019;10:37.

Mahr K, Riegler G, Hoi H. Parental risk management in relation to offspring defence: bad news for kids. Proc R Soc B. 2015;282:20141670.

Martin TE. Avian life-history evolution in relation to nest sites, nest predation, and food. Ecol Monogr. 1995;65:101-27.

Martin TE, Li PJ. Life history traits of open- vs cavity-nesting birds. Ecology. 1992;73:579-92.

Matthysen E. The Nuthatches. London: T \& AD Poyser Ltd A \& C Black; 1998.

Maziarz M, Piggott C, Burgess M. Predator recognition and differential behavioural responses of adult wood warblers Phylloscopus sibilatrix. Acta Ethol. 2018;21:13-20.

E M, Wang T, Wang S, Gong Y, Yu J, Wang L, Ou W, Wang H. Old nest material functions as an informative cue in making nest-site selection decisions in the European Kestrel Falco tinnunculus. Avian Res. 2019;10:43.

Møller AP, Díaz M, Liang W. Brood parasitism and proximity to human habitation. Behav Ecol. 2016;27:1314-9.

Montgomerie RD, Weatherhead PJ. Risks and rewards of nest defence by parent birds. Q Rev Biol. 1988;63:167-87.

Nad'o L, Kašová M, Krištín A, Kaňuch P. Cooperative nest-defence behaviour and territory quality in a resident and socially monogamous passerine. Ethology. 2018;124:514-26.

Newton I. The role of nest-sites in limiting the numbers of hole-nesting birds: a review. Biol Conserv. 1994;70:265-76.

Piao G, Wang S, Piao Z. The mammals of Changbai Mountain. Changchun: Jilin Science and Technology Press; 2013.

Polak M. Comparison of nest defence behaviour between two associate passerines. J Ethol. 2013;31:1-7.

Rice WR. Analyzing tables of statistical tests. Evolution. 1989;43:223-5.

Ricklefs RE. An analysis of nesting mortality in birds. Smith Contrib Zool. 1969:9:1-48. 
Ritchison SG. The nest defense behavior of eastern screech-owls: effects of nest stage, sex, nest type and predator location. Condor. 1993;95:288-96.

Smith JM. Parental investment-a prospective analysis. Anim Behav. 1977;25:1-9.

Solheim R. Caching behaviour, prey choice and surplus killing by Pygmy owls Glaucidium passerinum during winter, a functional response of a generalist predator. Ann Zool Fenn. 1984:21:301-8.

SordahI TA. The risks of avian mobbing and distraction behavior: an anecdotal review. Wilson Bull. 1990;102:349-52.

Strubbe D, Matthysen E. Experimental evidence for nest-site competition between invasive ring-necked parakeets Psittacula krameri and native nuthatches Sitta europaea. Biol Conserv. 2009;142:1588-94.

Sun Y, Wu H, Yao J, Jiang Y. The defensive effect of reduced hole size on the predator in Sitta europaea. J Northeast Normal Univ (nat Sci). 2017:49:123-6.

Suzuki TN. Parental alarm calls warn nestlings about different predatory threats. Curr Biol. 2011;21:R15-6.

Suzuki TN. Assessment of predation risk through referential communication in incubating birds. Sci Rep. 2015;5:10239.

Swaisgood RR, Owings DH, Rowe MP. Conflict and assessment in a predator-prey system: ground squirrels versus rattlesnakes. Anim Behav. 1999;57:1033-44.

Templeton CN, Greene E, Davis K. Allometry of alarm calls: black-capped chickadees encode information about predator size. Science. 2005;308:1934-7.

Trivers RL. Parental investment and sexual selection. In: Campbell B, editor. Sexual selection and the descent of man. Chicago: Aldine Publishing Company; 1972. p. 136-79.
Wesołowski T. Anti-predator adaptations in nesting Marsh Tits Parus palustris: the role of nest-site security. Ibis. 2002;144:593-601.

Wesołowski T, Rowiński P. Breeding behaviour of Nuthatch Sitta europaea in relation to natural hole attributes in a primeval forest. Bird Study. 2004;51:143-55.

Yorzinski JL, Platt ML. The difference between night and day: antipredator behavior in birds. J Ethol. 2012;30:211-8.

Yorzinski JL, Vehrencamp SL. The effect of predator type and danger level on the mob calls of the American crow. Condor. 2009;111:159-68.

Yu J, Wang L, Xing X, Yang C, Ma J, Møller AP, Wang H, Liang W. Barn swallows Hirundo rustica differentiate between common cuckoo and sparrowhawk in China: alarm calls convey information on threat. Behav Ecol Sociobiol. 2016;70:171-8.

Yu J, Lv W, Xu H, Bibi N, Yu Y, Jiang Y, Liang W, Wang H. Function of note strings in Japanese Tit alarm calls to the Common Cuckoo: a playback experiment. Avian Res. 2017a;81:22

Yu J, Xing X, Jiang Y, Liang W, Wang H, Møller AP. Alarm call-based discrimination between common cuckoo and Eurasian sparrowhawk in a Chinese population of great tits. Ethology. 2017b;1238:542-50.

Yu J, Lu H, Sun W, Liang W, Wang H, Møller AP. Heterospecific alarm-call recognition in two warbler hosts of common cuckoos. Anim Cogn. 2019;226:1149-57.

Yu J, Sun W, Liang W, Wang H, Møller AP. Differently sized cuckoos pose different threats to hosts. Curr Zool. 2020;66:247-53.
Ready to submit your research? Choose BMC and benefit from:

- fast, convenient online submission

- thorough peer review by experienced researchers in your field

- rapid publication on acceptance

- support for research data, including large and complex data types

- gold Open Access which fosters wider collaboration and increased citations

- maximum visibility for your research: over 100M website views per year

At BMC, research is always in progress.

Learn more biomedcentral.com/submissions 